\title{
ScIDioc
}

\author{
International Journal of Dentistry and Oral Science (IJDOS) \\ ISSN: 2377-8075
}

\section{Prevalence Of Gingivitis And Periodontal Diseases In Children Aged Between 6-12 Years}

Research Article

Palak Mayur Shah ${ }^{1}$, Ganesh Jeevanadan ${ }^{2 *}$, Manjari Chaudhary ${ }^{3}$

${ }^{1}$ Saveetha Dental College and Hospitals, Saveetha Institute of Medical and Technical Sciences (SIMATS), Saveetha University, Chennai - 600 077, India.

${ }^{2}$ Reader, Department of Pediatric Dentistry, Saveetha Dental College and Hospitals, Saveetha Institute of Medical and Technical Sciences (SIMATS), Saveetha University, Chennai - 600 077, India.

${ }^{3}$ Senior Lecturer, Department of Oral Medicine, Saveetha Dental College and Hospitals, Saveetha Institute of Medical and Technical Sciences (SIMATS), Saveetha University, Chennai - 600 077, India.

\section{Abstract}

Gingivitis is the inflammation of soft tissues without the migration or movement of the junctional epithelium in an apical direction. Characteristics of the conditions include redness, edema and bleeding gums. Gingivitis on prolonged duration leads to the formation of periodontitis.height. Several epidemiological studies on gingivitis and periodontitis has been conducted in various parts of India by dental professional.These epidemiological studies are helpful in planning and implementation of oral health programs. Moreover assessments of gingivitis and periodontitis in early stage will reduce the chance of tooth loss. Therefore, the aim of the study was to determine the prevalence of gingivitis and periodontal diseases among children aged between 6-12 years paediatric population. It was a retrospective study. Case sheets of 1596 pediatric patients reported to the Institution were reviewed. Information on the patient's age,gender,periodontal findings were collected from the electronic system in the college. The data are collected via the electronic database and compiled in an excel sheet. Incomplete or repeated patient records were excluded from the study. Descriptive and inferential (Chi-square test) were done. Mean age group of participants was 9.5 years. Out of 1596 patients, 1590 were diagnosed with gingivitis and 6 were diagnosed with periodontitis. In this study, we observed that the majority of patients were 10 years $(19.4 \%)$ and the least predominant age group was 6 years $(4.6 \%)$. Gingivitis was most common in 10 years, while periodontitis was seen most commonly in 11 years of age. Males $(57.8 \%)$ have a higher predilection to periodontal diseases than female $(42.2 \%)$ subjects. Association of the age and gender to gingivitis was found to be statistically non-significant. No significant association was seen between age and gender to periodontitis. We can conclude that gingivitis was more common than periodontitis. Gingivitis was most commonly diagnosed in the age group of 10 years and periodontitis was most commonly seen in 11 years of age. Age and gender has no prevalence on gingivitis and periodontitis.

Keywords: Age; Gender; Gingivitis; Periodontitis; Prevalence.

\section{Introduction}

Gingivitis is defined as bleeding of gums in at least one site of the tooth, which is the mildest form of gingivitis and most commonly diagnosed oral health problem. [1,2] Also, known as reversible dental plaque induced inflammation of the gingiva without clinical loss of attachment or increased bone loss. [3, 4] Gingivitis is of various types such as chronic gingivitis, which may or may not be plaque induced, drug-related, steroid hormone related, pregnancy gingivitis, etc. The most common type is the chronic gingivitis [5-7].

Gingivitis is a multifactorial etiology, which has been a result of many factors acting together. Most of the factors involved are bacterial biofilm, genetic, socioeconomic, iatrogenic, demographic and behavioral factors. [8-10] The most common factor is accumulation of plaque on the tooth surface, which further leads to inflammatory reaction causing redness, bleeding on probing, edema and sometimes pain. It is seen that gingivitis is the first

\footnotetext{
*Corresponding Author:

Ganesh Jeevanadan,

Reader, Department of Pediatric Dentistry, Saveetha Dental College and Hospitals, Saveetha Institute Of Medical and Technical Sciences Saveetha University, Chennai, India. Tel: 9884293869

E-mail: ganesh.sdc@saveetha.com

Received: May 08, 2021

Accepted: June 16, 2021

Published: June 25, 2021

Citation: Palak Mayur Shah, Ganesh Jeevanadan, Manjari Chaudhary. Prevalence Of Gingivitis And Periodontal Diseases In Children Aged Between 6-12 Years. Int J Dentistry Oral Sci. 2021;8(6):2889-2893. doi: http://dx.doi.org/10.19070/2377-8075-21000586
}

Copyright: Ganesh Jeevanadan ${ }^{\circ} 2021$. This is an open-access article distributed under the terms of the Creative Commons Attribution License, which permits unrestricted use, distribution and reproduction in any medium, provided the original author and source are credited. 
step to gingival diseases in children, adolescents or adults leading to the formation of periodontitis $[11,12]$.

Periodontitis affects the supporting dental structures, starting with the gingiva to the alveolar bone. $[13,14]$ This is known to be caused by complex communities of bacteria which are grown on the tooth surface leading to the destruction of the tooth. Periodontitis is an inflammatory response which is explicit leading to the tissue destruction $[15,16]$.

Periodontitis is known to be caused by pathological microorganism on the tooth surface which is accumulated due to poor oral hygiene. [17-19] It is known to develop when there is an increase in the number of gram negative bacteria and anaerobes. [20, 21] The species responsible for the periodontitis formation is Aggregatibacter, P. gingivalis, T. Denticola and other fungi and viruses such as candida albicans, or herpes are also seen to be a part of formation of gingivitis or periodontal disease. [22, 23] It is known to premature loss of tooth and leads to affecting the quality of life. Just as gingivitis is classified, periodontitis as well is classified into acute and chronic localized or generalized [24, 25]. Previously our team has a rich experience in working on various research projects across multiple disciplines [26-28, 3, 10, 29-38].

The aim of the study was to study the prevalence of gingivitis and periodontal diseases in children aged between age 6-12 years. The need for the study was aiming for preventive programs to improve the gingival and oral health, ensuring happy and healthy smiles in children.

\section{Material And Method}

\section{Study Design}

This study is a university setting study conducted in Saveetha Dental college,predominantly. Pros of the study include digital data. Ethical approval to utilize the case record was obtained from the institutional Ethical committee (ICE) of a private dental college,
Chennai, India - SDC/SIHEC/2020/DIASDATA/0619-0320.

Two examiners were involved. All Patients below 18 years of age were included in the study. Patients above 18 years and those with mental or physical disability were excluded from the study.

\section{Sampling}

It is a retrospective study, data collected from June 2019- April 2020. A total of 1596 case sheets were reviewed. Cross verification of data for error was done by presence of additional reviewers and by photographic evaluation. Consecutive sampling done to minimise sampling bias. It was generalized to patients below 18 yrs reported to the Institution.

\section{Data collection}

Data on the patient's age group, periodontal findings, Gender were collected from an electronic system in the college. Data was entered in Excel in a methodical manner and imported in spss software. Incomplete or repeated patient records were excluded from the study. Analytics: IBM spss 2.0 software was used for data analysis. Independent variables included in the study were Age, Gender of the subject. Dependent variables included are the patient's periodontal findings. Descriptive statistics include frequency of distribution of patient's age, gender.

\section{Result And Discussion}

Mean age group of the participants in the study was 9.5 years. Frequency distribution of the patients was done by the age groups, where the most common age group was 10 years $(19.4 \%)$, followed by 11 years $(17.6 \%)$. The least common age group was 6 years $(4.6 \%)$. - [Figure 1]. Frequency distribution of the patients was done by gender, where the most common gender was males $(57.8 \%)$ more than female subjects. (42.2\%) - [Figure 2]. Gingivitis $(99.6 \%)$ was found to be more common in 10 years, and prevalence of periodontitis was most common in 11 years $(0.4 \%)$ among the subjects - [Figure 3]

Figure 1. Bar graph represents the age group of patients with periodontal disease. $\mathrm{X}$-axis represents the age of the patient and $\mathrm{Y}$-axis represents the percentage of patients with periodontal disease. Children at the age of 10 years (Yellow) had more periodontal disease compared to other age groups.

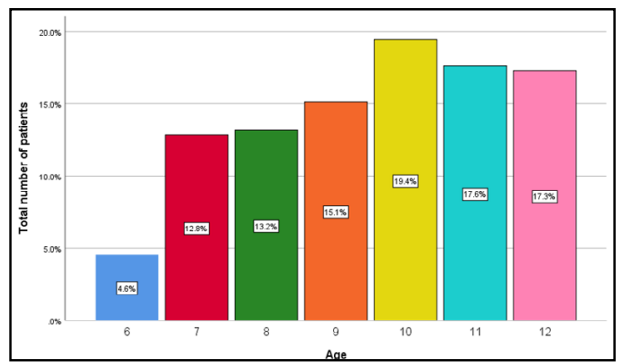

Figure 2. Bar graph represents the gender of patients with periodontal disease. $\mathrm{X}$-axis represents the gender of the patient and Y-axis represents the percentage of patients with periodontal disease. Male (Red) children had more periodontal disease compared to female (Blue) children.

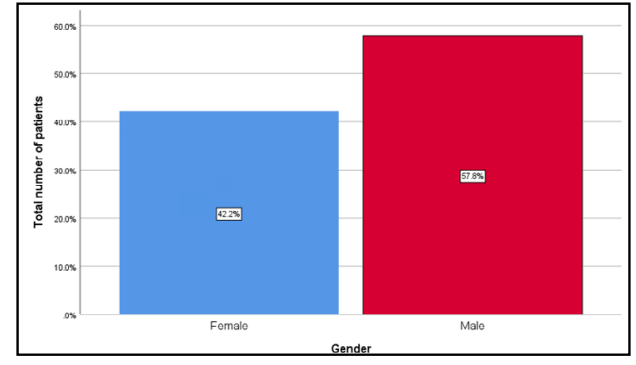


Association was done between the age of the patient and gingivitis, which was found to be statistically non-significant. $(p=0.329)$, proving there was no association between age and gingivitis. [Figure 4] Association was done between the gender of the patient and gingivitis, which was found to be statistically non-significant. $(p=0.132)$, proving there was no association between the gender and gingivitis. [Figure 5]

Association was done between the age of the patient and periodontitis, which was found to be statistically non-significant. $(p=0.329)$, proving there was no association between age and periodontitis. [Figure 6] Association was done between the gender of the patient and periodontitis, which was found to be statistically non-significant. $(p=0.132)$, proving there was no association be- tween the gender and gingivitis. [Figure 7]

Oral health is essential for general health and well being throughout life and is known as a marker for the overall health status of the child. In our study we observed that out of 1596 children, 1590 were diagnosed with gingivitis and the other 6 were diagnosed with periodontitis.

Unlike the studies reported by Chauhan et.al, it was diagnosed that increased cases of healthy gingiva were present than gingivitis. It was higher when compared to Gaengler et.al, [39] and LeRoy [40], where it was diagnosed that almost $99.4 \%$ of the children population was diagnosed with the gingivitis, whereas Hagosan and Levoy reported that gingival cases were diagnosed as $59 \%$ and $84.3 \%$ respectively. Studies reported by Xiao et.al, [41] and

Figure 3. Bar graph represents the frequency of patients with periodontal diseases. X-axis represents the gingival diseases and Y-axis represents the total number of patients. Commonest periodontal disease among children was gingivitis (Blue) compared to periodontitis (Red).

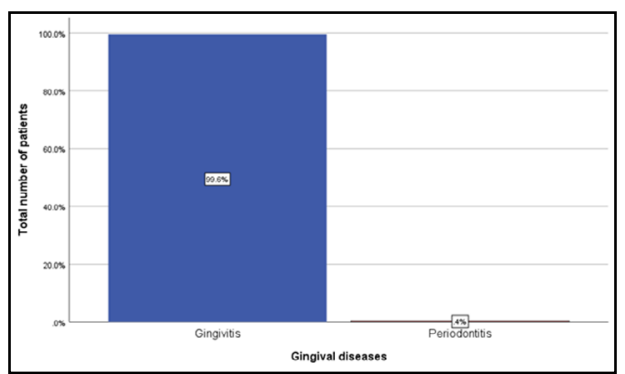

Figure 4. Bar graph represents the association of the age of patients to gingivitis. $\mathrm{X}$-axis represents the age of the patient and $\mathrm{Y}$-axis represents the number of patients with gingivitis. No gingivitis (Blue), gingivitis (Red). Chi-square test was done and association was found to be statistically non-significant (Pearson's chi-square test, $\mathrm{p}=0.329(\mathrm{p}>0.05)$, proving that there was no association between the age and gingivitis.

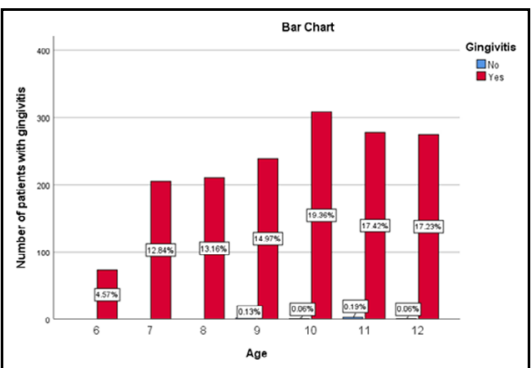

Figure 5. Bar graph represents the association of the gender of patients to gingivitis. X-axis represents the gender of the patient and $\mathrm{Y}$-axis represents the number of patients with gingivitis. No gingivitis (Blue), gingivitis (Red). Chi-square test was done and association was found to be statistically non-significant (Pearson's chi-square test, $\mathrm{p}=0.132(\mathrm{p}>0.05)$, proving that there was no association between the gender and gingivitis.

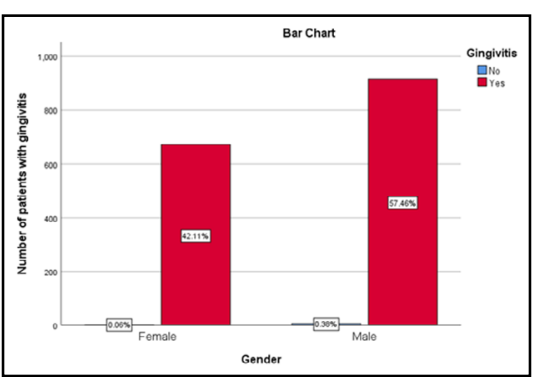

Figure 6. Bar graph represents the association of the age of patients to periodontitis. X-axis represents the age of the patient and $\mathrm{Y}$-axis represents the number of patients with periodontitis. No periodontitis (Blue), Periodontitis (Red). Chi-square test was done and association was found to be statistically non-significant (Pearson's chi-square test, $\mathrm{p}=0.329(\mathrm{p}>0.05)$, proving that there was no association between the age and periodontitis.

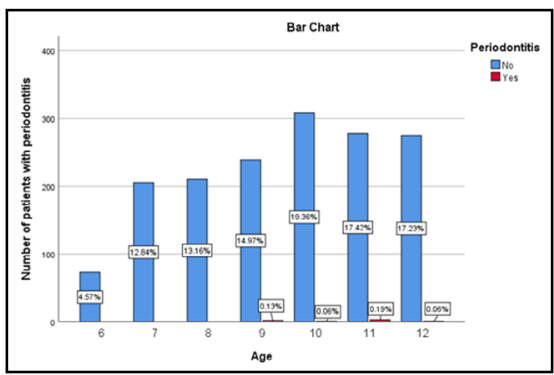


Figure 7. Bar graph represents the association of gender of the patients to periodontitis. X-axis represents the gender of the patient and Y-axis represents the number of patients with periodontitis. No periodontitis (Blue), Periodontitis (Red). Chi-square test was done and association was found to be statistically non-significant (Pearson's chi-square test, $\mathrm{p}=0.132(\mathrm{p}>0.005)$, proving that there was no association between the gender and periodontitis.

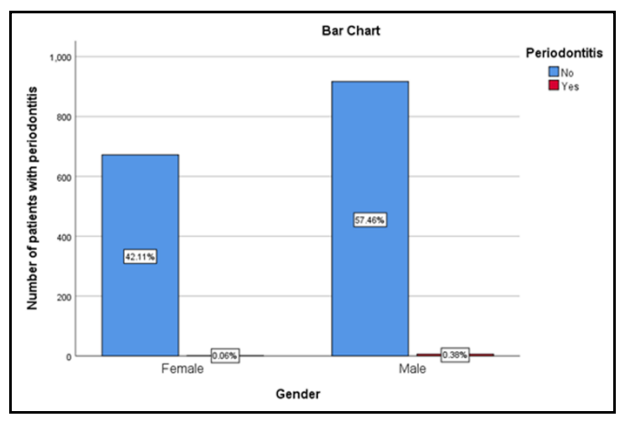

Bhavya et.al, [42] reported that $100 \%$ of the population were diagnosed with gingival diseases, which were the highest compared to all other findings.

The high prevalence was attributed towards the oral hygiene of the tooth, the sexes at different ages in them. Furthermore, high prevalence diseases of the gingiva and periodontitis $(40.2 \%)$ to $10-12$ years old and the lease prevalence was seen in $6-7(14.5 \%)$ When gingival index was considered $81 \%$ of the population examined had gingivitis out of which $65 \%$ had moderate gingivitis and $15 \%$ mild gingivitis. In contrast to our results Vineeth et al [43], who did the study on school going children of rural areas of India using Loe and Silness index, have reported $84.37 \%$ overall prevalence which is high. Similar high prevalence was seen in studies of Pandit et.al, [44] that the gingival status of school going children in different parts of India.According to the present study, the females were seen to be higher in diagnosis for gingival diseases than males. Although in most countries sex difference was greater. Our institution is passionate about high quality evidence based research and has excelled in various fields [45-55].

The factors could be that women could be more careful about their health than male or maybe the lower oral health maintenance $[23,56]$. The limitations of the study included poor socioeconomic status, poor oral hygiene, single center study and poor material education. Future studies acknowledge the risk factors, educate the dental students, early diagnosis and keep motivating patients for better oral hygiene.

\section{Conclusion}

Within the limits of the study, we can conclude that the prevalence of gingivitis was most common in 10 years, while periodontitis was most common in 11 years. However, there was no statistically significance between the age and gender to gingivitis and periodontitis.

\section{Authors Contributions}

First author (Palak Mayur Shah) performed the analysis, and interpretation and wrote the manuscript. Second author (Dr. Ganesh Jeevanadan) contributed to conception, data design, analysis, interpretation and critically revised the manuscript. Third author (Dr.Manjari Chaudhary) participated in the study and revised the manuscript. All the three authors have discussed the results and contributed to the final manuscript.

\section{References}

[1]. Elias-Boneta AR, Ramirez K, Rivas-Tumanyan S, Murillo M, Toro MJ. Prevalence of gingivitis and calculus in 12-year-old Puerto Ricans: a crosssectional study. BMC Oral Health. 2018 Jan 19;18(1):13.Pubmed PMID: 29351752.

[2]. Somasundaram S, Ravi K, Rajapandian K, Gurunathan D. Fluoride Content of Bottled Drinking Water in Chennai, Tamilnadu. J Clin Diagn Res. 2015 Oct;9(10):ZC32-4.Pubmed PMID: 26557612.

[3]. Gurunathan D, Shanmugaavel AK. Dental neglect among children in Chennai. J Indian Soc Pedod Prev Dent. 2016 Oct 1;34(4):364-9.

[4]. Jeevanandan G. Kedo-S Paediatric Rotary Files for Root Canal Preparation in Primary Teeth - Case Report. J Clin Diagn Res. 2017 Mar;11(3):ZR03ZR05.Pubmed PMID: 28511532.

[5]. Rodan R, Khlaifat F, Smadi L, Azab R, Abdalmohdi A. Prevalence and severity of gingivitis in school students aged 6-11 years in Tafelah Governorate, South Jordan: results of the survey executed by National Woman's Health Care Center. BMC Res Notes. 2015 Nov 9;8:662.Pubmed PMID: 26552995.

[6]. Mesele M, Degu G, Gebrehiwot H. Prevalence and associated factors of goiter among rural children aged 6-12 years old in Northwest Ethiopia, cross-sectional study. BMC Public Health. 2014 Feb 7;14:130.Pubmed PMID: 24502377.

[7]. Govindaraju L, Jeevanandan G, Subramanian EM. Knowledge and practice of rotary instrumentation in primary teeth among indian dentists: A questionnaire survey. Int. J. Oral Health Dent. 2017 Mar 1;9(2):45.

[8]. Govindaraju L, Jeevanandan G, Subramanian EMG. Comparison of quality of obturation and instrumentation time using hand files and two rotary file systems in primary molars: A single-blinded randomized controlled trial. Eur J Dent. 2017 Jul-Sep;11(3):376-379.Pubmed PMID: 28932150.

[9]. Ramakrishnan M, Bhurki M. Fluoride, Fluoridated Toothpaste Efficacy And Its Safety In Children-Review. Int. j.pharm. res. 2018 Oct 1;10(04):109-14.

[10]. Govindaraju L, Gurunathan D. Effectiveness of Chewable Tooth Brush in Children-A Prospective Clinical Study. J Clin Diagn Res. 2017 Mar;11(3):ZC31-ZC34.Pubmed PMID: 28511505.

[11]. Vadiakas G, Oulis CJ, Tsinidou K, Mamai-Homata E, Polychronopoulou A. Oral hygiene and periodontal status of 12 and 15-year-old Greek adolescents. A national pathfinder survey. Eur Arch Paediatr Dent. 2012 Feb $1 ; 13(1): 11-20$.

[12]. Naseeb AA. National Oral Health Survey of Oral Health Status of Bahraini School Children Aged 6, 12 and 15 Year Old. Dental News. 2016 Sep;23:12-29.

[13]. Baelum V, Fejerskov O, Karring T. Oral hygiene, gingivitis and periodontal breakdown in adult Tanzanians. J Periodontal Res. 1986 May;21(3):221-32. Pubmed PMID: 2941555.

[14]. Packiri S, Gurunathan D, Selvarasu K. Management of paediatric oral ranula: a systematic review. J. Clin. Diagnostic Res. 2017 Sep;11(9):ZE06-9.

[15]. Clerehugh V, Tugnait A. Diagnosis and management of periodontal diseases in children and adolescents. Periodontol. 2000. 2001 Jun;26(1):146-68.

[16]. Govindaraju L, Jeevanandan G, Subramanian E. Clinical Evaluation of Quality of Obturation and Instrumentation Time using Two Modified Rotary File Systems with Manual Instrumentation in Primary Teeth. J Clin Diagn Res. 2017 Sep;11(9):ZC55-ZC58.Pubmed PMID: 29207834.

[17]. Mittal M, Chaudhary P, Chopra R, Khattar V. Oral health status of 5 years and 12 years old school going children in rural Gurgaon, India: an epidemiological study. J Indian Soc Pedod Prev Dent. 2014 Jan-Mar;32(1):3-8. Pubmed PMID: 24531594.

[18]. Ravikumar D, Jeevanandan G, Subramanian EM. Evaluation of knowledge among general dentists in treatment of traumatic injuries in primary teeth: 
A cross-sectional questionnaire study. Eur. J. Dent. 2017 Apr;11(02):232-7.

[19]. Subramanyam D, Gurunathan D, Gaayathri R, Vishnu Priya V. Comparative evaluation of salivary malondialdehyde levels as a marker of lipid peroxidation in early childhood caries. Eur J Dent. 2018 Jan-Mar;12(1):67-70. Pubmed PMID: 29657527.

[20]. Panchal V, Jeevanandan G, Subramanian E. Comparison of instrumentation time and obturation quality between hand K-file, H-files, and rotary Kedo-S in root canal treatment of primary teeth: A randomized controlled trial. J Indian Soc Pedod Prev Dent. 2019 Jan-Mar;37(1):75-79.Pubmed PMID: 30804311.

[21]. Christabel SL, Gurunathan D. Prevalence of type of frenal attachment and morphology of frenum in children, Chennai, Tamil Nadu. World J Dent. 2015 Oct;6(4):203-7.

[22]. Jose A, Joseph MR. Prevalence of dental health problems among school going children in rural Kerala. J Indian Soc Pedod Prev Dent. 2003 Dec;21(4):147-51.Pubmed PMID: 14765615

[23]. Lakshmanan L, Mani G, Jeevanandan G. Assessing the quality of obturation and instrumentation time using Kedo-S files, Reciprocating files and Hand K-files. Braz. Dent. Sci. 2020;23.

[24]. Das UM, Beena JP, Azher U. Oral health status of 6- and 12-year-old school going children in Bangalore city: an epidemiological study. J Indian Soc Pedod Prev Dent. 2009 Jan-Mar;27(1):6-8.Pubmed PMID: 19414967.

[25]. Sharva V, Reddy V, Bhambal A, Agrawal R. Prevalence of Gingivitis among Children of Urban and Rural Areas of Bhopal District, India. J Clin Diagn Res. 2014 Nov;8(11):ZC52-4.Pubmed PMID: 25584317.

[26]. Hafeez N. Accessory foramen in the middle cranial fossa. Res J Pharm Technol. 2016 Nov 1;9(11):1880.

[27]. Krishnan RP, Ramani P, Sherlin HJ, Sukumaran G, Ramasubramanian A, Jayaraj G, et al. Surgical Specimen Handover from Operation Theater to Laboratory: A Survey. Ann Maxillofac Surg. 2018 Jul-Dec;8(2):234-238. Pubmed PMID: 30693238

[28]. Somasundaram S, Ravi K, Rajapandian K, Gurunathan D. Fluoride Content of Bottled Drinking Water in Chennai, Tamilnadu. J Clin Diagn Res. 2015 Oct;9(10):ZC32-4.Pubmed PMID: 26557612.

[29]. Felicita AS. Orthodontic extrusion of Ellis Class VIII fracture of maxillary lateral incisor - The sling shot method. Saudi Dent J. 2018 Jul;30(3):265269.Pubmed PMID: 29942113.

[30]. Kumar S, Rahman RE. Knowledge, awareness, and practices regarding biomedical waste management among undergraduate dental students. Asian J Pharm Clin Res. 2017;10(8):341.

[31]. Sneha S. Knowledge and awareness regarding antibiotic prophylaxis for infective endocarditis among undergraduate dental students. Asian J. Pharm. Clin. Res. 2016 Oct 1:154-9.

[32]. Dhinesh B, Lalvani JI, Parthasarathy M, Annamalai K. An assessment on performance, emission and combustion characteristics of single cylinder diesel engine powered by Cymbopogon flexuosus biofuel. Energy Convers Manage. 2016 Jun 1;117:466-74.

[33]. Choudhari S, Thenmozhi MS. Occurrence and Importance of Posterior Condylar Foramen. LATERALITY. 2016 Aug 28;8:11-43.

[34]. Paramasivam A, Vijayashree Priyadharsini J, Raghunandhakumar S. N6adenosine methylation (m6A): a promising new molecular target in hypertension and cardiovascular diseases. Hypertens Res. 2020 Feb;43(2):153154.Pubmed PMID: 31578458.

[35]. Wu F, Zhu J, Li G, Wang J, Veeraraghavan VP, Krishna Mohan S, et al. Biologically synthesized green gold nanoparticles from Siberian ginseng induce growth-inhibitory effect on melanoma cells (B16). Artif Cells Nanomed Biotechnol. 2019 Dec;47(1):3297-3305.Pubmed PMID: 31379212.

[36]. Palati S, Ramani P, Shrelin HJ, Sukumaran G, Ramasubramanian A, Don $\mathrm{KR}$, et al. Knowledge, Attitude and practice survey on the perspective of oral lesions and dental health in geriatric patients residing in old age homes. Indian J Dent Res. 2020 Jan-Feb;31(1):22-25.Pubmed PMID: 32246676.

[37]. Saravanan M, Arokiyaraj S, Lakshmi T, Pugazhendhi A. Synthesis of silver nanoparticles from Phenerochaete chrysosporium (MTCC-787) and their antibacterial activity against human pathogenic bacteria. Microb Pathog. 2018 Apr;117:68-72.Pubmed PMID: 29427709.

[38]. Vijayakumar Jain S, Muthusekhar MR, Baig MF, Senthilnathan P, Logana- than S, Abdul Wahab PU, et al. Evaluation of Three-Dimensional Changes in Pharyngeal Airway Following Isolated Lefort One Osteotomy for the Correction of Vertical Maxillary Excess: A Prospective Study. J Maxillofac Oral Surg. 2019 Mar;18(1):139-146.Pubmed PMID: 30728705.

[39]. Gaengler P. Prevalence and distribution of gingivitis, periodontitis and missing teeth in adolescents and adults according to GPM/T index. Community Dent Oral Epidemiol. 1984 Aug;12(4):255-9.Pubmed PMID: 6590178.

[40]. Leroy R, Jara A, Martens L, Declerck D. Oral hygiene and gingival health in Flemish pre-school children. Community Dent Health. 2011 Mar;28(1):7581.Pubmed PMID: 21485240.

[41]. Xiao Y. An oral health survey and prevention of dental caries among school children in Shenzhen. 2009 Jan 1:1-0.

[42]. Shyagali TR, Bhayya DP. Study of oral hygiene status and prevalence of gingival diseases in 10-12-year-old school children in Sholapur City, India. Niger. Dent. J. 2011;18.

[43]. Dhar V, Jain A, Van Dyke TE, Kohli A. Prevalence of gingival diseases, malocclusion and fluorosis in school-going children of rural areas in Udaipur district. J Indian Soc Pedod Prev Dent. 2007 Apr-Jun;25(2):103-5.Pubmed PMID: 17660647.

[44]. Pandit K, Kannan AT, Sarana A, Aggarwal K. Periodontal disease and dental caries in primary school children in rural areas of Delhi. Indian J Pediatr. 1986 Jul-Aug;53(4):525-9.Pubmed PMID: 3492445.

[45]. Vijayashree Priyadharsini J. In silico validation of the non-antibiotic drugs acetaminophen and ibuprofen as antibacterial agents against red complex pathogens. J Periodontol. 2019 Dec;90(12):1441-1448.Pubmed PMID: 31257588.

[46]. PC J, Marimuthu T, Devadoss P, Kumar SM. Prevalence and measurement of anterior loop of the mandibular canal using CBCT: A cross sectional study. Clin Implant Dent Relat Res. 2018 Apr 6;20(4):531-4.

[47]. Ramesh A, Varghese S, Jayakumar ND, Malaiappan S. Comparative estimation of sulfiredoxin levels between chronic periodontitis and healthy patients-A case-control study. J Periodontol. 2018 Oct;89(10):1241-8.

[48]. Ramadurai N, Gurunathan D, Samuel AV, Subramanian E, Rodrigues SJ. Effectiveness of $2 \%$ Articaine as an anesthetic agent in children: randomized controlled trial. Clin Oral Investig. 2019 Sep;23(9):3543-50.

[49]. Sridharan G, Ramani P, Patankar S, Vijayaraghavan R. Evaluation of salivary metabolomics in oral leukoplakia and oral squamous cell carcinoma. J. Oral Pathol. Med. 2019 Apr;48(4):299-306.

[50]. Ezhilarasan D, Apoorva VS, Ashok Vardhan N. Syzygium cumini extract induced reactive oxygen species-mediated apoptosis in human oral squamous carcinoma cells. J Oral Pathol Med. 2019 Feb;48(2):115-121.Pubmed PMID: 30451321

[51]. Mathew MG, Samuel SR, Soni AJ, Roopa KB. Evaluation of adhesion of Streptococcus mutans, plaque accumulation on zirconia and stainless steel crowns, and surrounding gingival inflammation in primary molars: randomized controlled trial. Clin Oral Investig. 2020 Sep;24(9):1-6.Pubmed PMID: 31955271

[52]. Samuel SR. Can 5-year-olds sensibly self-report the impact of developmental enamel defects on their quality of life? Int J Paediatr Dent. 2021 Mar;31(2):285-286.Pubmed PMID: 32416620

[53]. R H, Ramani P, Ramanathan A, R JM, S G, Ramasubramanian A, et al. CYP2 C9 polymorphism among patients with oral squamous cell carcinoma and its role in altering the metabolism of benzo[a]pyrene. Oral Surg Oral Med Oral Pathol Oral Radiol. 2020 Sep;130(3):306-312.Pubmed PMID: 32773350.

[54]. Chandrasekar R, Chandrasekhar S, Sundari KKS, Ravi P. Development and validation of a formula for objective assessment of cervical vertebral bone age. Prog Orthod. 2020 Oct 12;21(1):38.Pubmed PMID: 33043408.

[55]. Vijayashree Priyadharsini J, Smiline Girija AS, Paramasivam A. In silico analysis of virulence genes in an emerging dental pathogen A. baumannii and related species. Arch Oral Biol. 2018 Oct;94:93-98.Pubmed PMID: 30015217.

[56]. Jeevanandan G, Govindaraju L. Clinical comparison of Kedo-S paediatric rotary files vs manual instrumentation for root canal preparation in primary molars: a double blinded randomised clinical trial. Eur Arch Paediatr Dent 2018 Aug;19(4):273-278.Pubmed PMID: 30003514. 